\title{
A Marine Isolate of Bacillus pumilus Secretes a Pumilacidin Active against Staphylococcus aureus
}

\author{
Anella Saggese ${ }^{1}$, Rosanna Culurciello ${ }^{1}$, Angela Casillo ${ }^{2}$, Maria Michela Corsaro ${ }^{2}$, Ezio Ricca ${ }^{1}$ \\ and Loredana Baccigalupi ${ }^{1, *}$ \\ 1 Department of Biology, Federico II University of Naples, 80126 Naples, Italy; \\ ornellasaggese2010@libero.it (A.S.); rosanna.culurciello@gmail.com (R.C.); ericca@unina.it (E.R.) \\ 2 Department of Chemical Sciences, Federico II University of Naples, 80126 Naples, Italy; \\ angela.casillo@unina.it (A.C.); mariamichela.corsaro@unina.it (M.M.C.) \\ * Correspondence: lorbacci@unina.it; Tel.: +39-081-679-037
}

Received: 24 April 2018; Accepted: 22 May 2018; Published: 24 May 2018

\begin{abstract}
Producing antimicrobials is a common adaptive behavior shared by many microorganisms, including marine bacteria. We report that SF214, a marine-isolated strain of Bacillus pumilus, produces at least two different molecules with antibacterial activity: a molecule smaller than $3 \mathrm{kDa}$ active against Staphylococcus aureus and a molecule larger than $10 \mathrm{kDa}$ active against Listeria monocytogenes. We focused our attention on the anti-Staphylococcus molecule and found that it was active at a wide range of $\mathrm{pH}$ conditions and that its secretion was dependent on the growth phase, medium, and temperature. A mass spectrometry analysis of the size-fractionated supernatant of SF214 identified the small anti-Staphylococcus molecule as a pumilacidin, a nonribosomally synthesized biosurfactant composed of a mixture of cyclic heptapeptides linked to fatty acids of variable length. The analysis of the SF214 genome revealed the presence of a gene cluster similar to the srfA-sfp locus encoding the multimodular, nonribosomal peptide synthases found in other surfactant-producing bacilli. However, the srfA-sfp cluster of SF214 differed from that present in other surfactant-producing strains of B. pumilus by the presence of an insertion element previously found only in strains of B. safensis.
\end{abstract}

Keywords: SF214; B. pumilus; antimicrobials; lipopeptides; surfactants; surfactin; pumilacidin

\section{Introduction}

The emergence of pathogenic antibiotic-resistant bacteria urges for an increased attention to the identification and characterization of new antimicrobials. Marine organisms have remarkably contributed to the discovery and production of novel antimicrobials, and in general, of biomolecules of pharmaceutical relevance. Indeed, over 50\% of all drugs approved in the U.S. between 1981 and 2002 are based on either marine bioactive compounds or their synthetic analogs [1]. However, for its enormous biodiversity, the marine environment is still considered a largely unexplored source of antimicrobial agents [1,2]. Sponges, marine algae, and bacteria all produce a large variety of secondary metabolites of remarkable chemical diversity with potential antimicrobial activity [2]. In recent years, terpenoids, steroids, phenolic compounds, alkaloids, polyketides, and peptides produced by marine organisms have shown antibacterial, antiviral, and antifungal activities [2]. Bacterial peptides and lipopeptides with antimicrobial activity are probably the most promising molecules for future biomedical applications because of their relative ease of overproduction and purification. Over the years, several examples of peptides and lipopeptides produced by marine bacteria and showing antimicrobial activities have been reported. These include the cyclic lipopeptides maribasins A and B, produced by Bacillus marinus and active against several phytopathogens and fungi [3]; the lipopeptide tauramamide, produced by Brevibacillus laterosporus and selectively active against Enterococcus cells [4]; 
and a thiopeptide produced by Nocardiopsis sp. TP-1161 and active against a wide range of bacteria [5]. Often, the synthesis of antimicrobial peptides and lipopeptides does not rely on the translational machinery, but on multimodular enzymes, the nonribosomal peptide synthases (NRPS) [6]. These enzymatically produced peptides are biosurfactants with antimicrobial activity and often contain cyclic structures, D-amino acids, and various modifications such as $\mathrm{N}$-methyl and $\mathrm{N}$-formyl groups or glycosylation, acylation, or hydroxylation [7]. The peptide moiety of these biosurfactants is generally formed by 7-15 residues (hydrophilic head) and is bound to a fatty acid (hydrophobic tail) of variable lengths [8-10]. Various species of the Bacillus genus produce similar nonribosomal lipopeptides grouped in the surfactin, iturin, or fengycin families [11]. Members of the surfactin family are surfactin, produced by strains of B. subtilis and B. amyloliquefaciens; lichenysin, produced by strains of B. licheniformis; and pumilacidin, produced by strains of B. pumilus and B. safensis [12]. The best characterized of these is surfactin, a mixture of cyclic lipopeptides formed by a heptapeptide with the sequence Glu-(Leu/Ile/Val)-Leu-(Leu/Ile/Val)-Asp-Leu-(Leu/Ile/Val) and a beta-hydroxy fatty acid with chains of length ranging from 13 to 16 carbons and differing mostly in the fatty acid substitutions [12]. While surfactins have a wide spectrum of activity against various Gram-positive and Gram-negative bacteria [13,14], pumilacidins have antiviral [15] and antimotility [16] activities, but no data are currently available on their antibacterial activity.

We screened a collection of marine-isolated bacteria, all Gram-positive, aerobic endospore formers belonging to the Bacillus genus, to search for strains producing molecules with antimicrobial activity against a panel of target bacteria. The only strain in our screen that showed antibacterial activity was Bacillus pumilus SF214, a previously characterized strain, shown to produce a water-soluble yellow-orange pigment [17]. The still-uncharacterized pigment is essential to protect SF214 cells against oxidative stress and its synthesis is highly regulated, with a maximum of production in minimal media at $25^{\circ} \mathrm{C}$ and during the stationary phase of growth [18,19]. The aim of this work was then to provide a characterization of the antibacterial molecules produced and secreted by SF214 and of the genes involved in their biosynthesis.

\section{Results and Discussion}

\subsection{SF214 Secretes Two Antimicrobials Active Against Staphylococcus aureus or Listeria monocytogenes}

In order to identify new molecules with antimicrobial activity, we used a collection of fifteen Bacillus strains all isolated from marine samples (Supplementary Materials Table S1). All strains were grown for $16 \mathrm{~h}$ at $30^{\circ} \mathrm{C}$ in LB (Luria-Bertani) medium, the culture supernatants were filter-sterilized, and $10 \mu \mathrm{L}$ of each supernatant was used for antimicrobial plate assays with a panel of target bacterial strains. Only one of the fifteen strains tested, SF214, showed antimicrobial activity against Staphylococcus aureus and Listeria monocytogenes (Supplementary Materials Table S2). To characterize the antimicrobial activity of SF214, the supernatant was size-fractionated and the various fractions tested in antimicrobial plate assays against the two sensitive target bacteria. While the molecule active against $S$. aureus was in the fraction smaller than $3 \mathrm{kDa}$, the one active against L. monocytogenes was in the fraction of molecules larger than $10 \mathrm{kDa}$ (Figure 1), indicating that SF214 produces and secretes at least two different molecules with antimicrobial activity.

\subsection{Production of Both Antimicrobials Is Strictly Regulated}

SF214 was grown at various temperatures and in different growth media. The supernatants of the various growth experiments were size-fractionated and the fractions smaller than $3 \mathrm{kDa}$ and larger than $10 \mathrm{kDa}$ tested against S. aureus and L. monocytogenes, respectively. As shown in Table 1, the anti-Staphylococcus activity was stronger in supernatants obtained with minimal (S7) medium than in rich (LB or BHI, Brain Heart Infusion) or in sporulation-inducing (DS, Difco Sporulation) media and was stronger in supernatants of cell growth at $25^{\circ} \mathrm{C}$ than at 30 or $37^{\circ} \mathrm{C}$. The anti-Listeria activity was similarly strong in supernatants obtained with BHI and S7 media, while it was slightly less strong in 
LB or DS media. In the minimal S7 medium, the anti-Listeria activity was similarly strong at $25^{\circ} \mathrm{C}$ and $30^{\circ} \mathrm{C}$ and slightly less strong at $37^{\circ} \mathrm{C}$ (Table 1$)$.
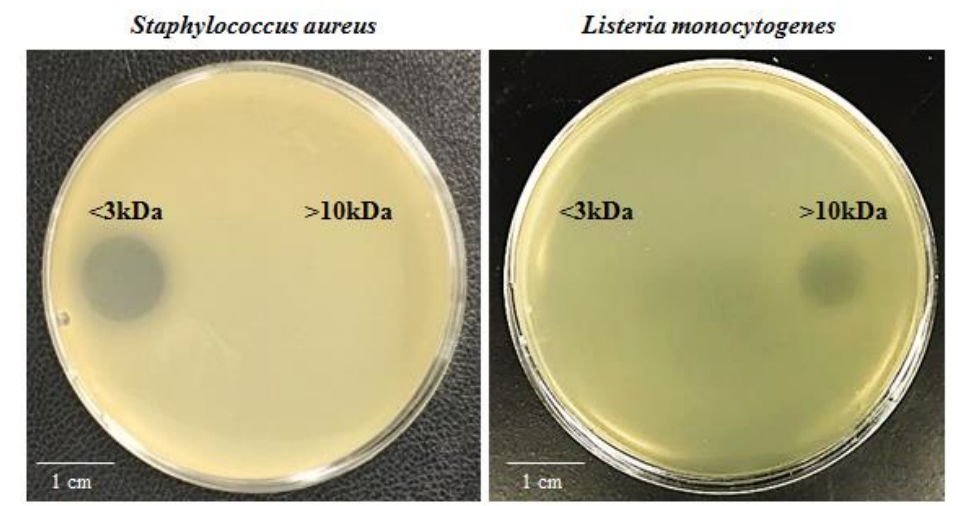

Figure 1. Antimicrobial plate assays. Fractions of Bacillus pumilus SF214 supernatant were tested against target bacteria. The fraction containing molecules smaller than $3 \mathrm{kDa}$ was active against S. aureus and not against L. monocytogenes, while the fraction containing molecules larger than $10 \mathrm{kDa}$ was active against $L$. monocytogenes and not against $S$. aureus.

Table 1. Production of antimicrobials at various growth conditions.

\begin{tabular}{cccc}
\hline Medium & Temperature $\left({ }^{\circ} \mathbf{C}\right)$ & $\begin{array}{c}\text { Supernatant Activity } \\
\text { a } \\
\text { L. monocytogenes }\end{array}$ & $\begin{array}{c}\text { Supernatant Activity }{ }^{\text {a }} \\
<3 \text { kDa against } \\
\text { S. aureus }\end{array}$ \\
\hline $\begin{array}{c}\text { LB (Luria-Bertani) } \\
\text { BHI (Brain Heart } \\
\text { Infusion) }\end{array}$ & 25 & 7 & 5 \\
DS (Difco & 25 & 10 & 5 \\
Sporulation) & 25 & 7 & 5 \\
S7 & 25 & 10 & 10 \\
S7 & 30 & 10 & 7 \\
S7 & 37 & 5 & 5 \\
\hline
\end{tabular}

BHI broth was supplemented with $0.1 \%$ glucose. ${ }^{\text {a }}$ Diameter $(\mathrm{mm})$ of the inhibition halo in plate assays.

Production of the two antimicrobial molecules was also analyzed during growth in S7 medium at $25^{\circ} \mathrm{C}$. As shown in Figure 2, while the anti-Listeria molecule was produced during the exponential and stationary growth phases and the increase of activity paralleled the increase in the number of cells, production of the anti-Staphylococcus molecule only started in the late stationary growth phase and continued during the stationary phase, revealing the typical pattern of synthesis of secondary metabolites. The production profile of the antimicrobial smaller than $3 \mathrm{kDa}$ resembled that of the pigment produced by SF214 cells. Indeed, the pigment was also produced in the late stationary phase of growth, preferentially at $25{ }^{\circ} \mathrm{C}$ in minimal (S7) medium [17]. However, single mutants of SF214 that did not produce [18] or produced a larger amount [19] of pigment showed an anti-Staphylococcus activity identical to that of the wild-type strain (data not shown), indicating that the pigment and the antimicrobial molecules were independent molecules. 
A

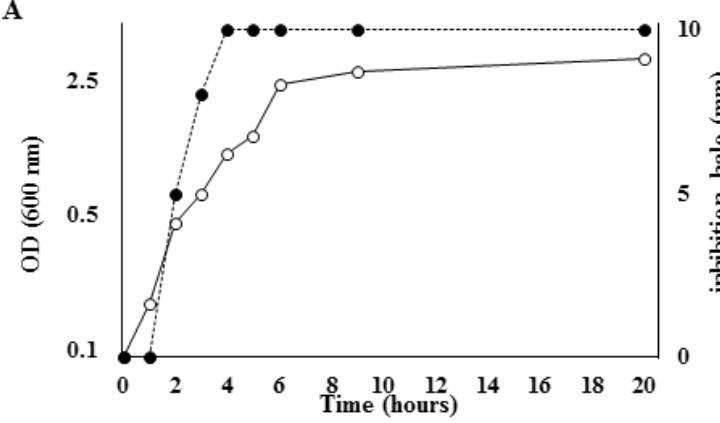

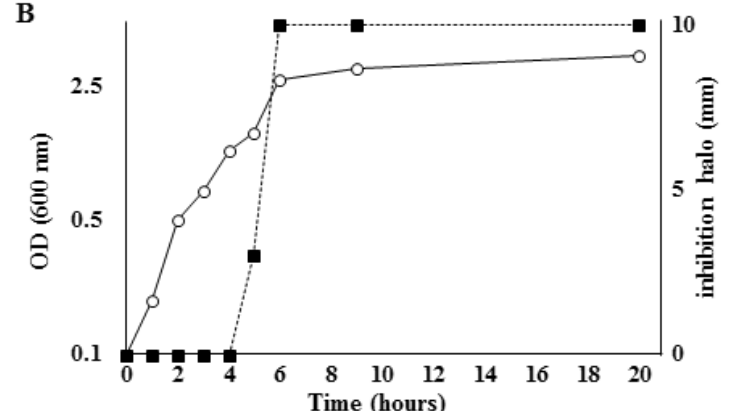

Figure 2. Production of the antimicrobials during growth. SF214 was grown in minimal (S7) medium at $25{ }^{\circ} \mathrm{C}$ and the growth curve reported (white symbols). Aliquots of the cell culture were collected at various times, size-fractionated, and tested against the target bacteria. Dashed lines indicate the antimicrobial activity (diameter in mm of inhibition halo) of the fraction larger than $10 \mathrm{kDa}$ against L. monocytogenes (A) and of the fraction smaller than $3 \mathrm{kDa}$ against $S$. aureus (B).

Results of Table 1 and Figure 2 thus suggest that SF214 produces a secondary metabolite, smaller than $3 \mathrm{kDa}$ and active against $S$. aureus and a product of the primary metabolism, larger than $10 \mathrm{kDa}$ and active against $L$. monocytogenes. We decided to focus our attention on the secondary metabolite active against Staphylococcus aureus for all further experiments.

\subsection{The Anti-Staphylococcus Molecule Was Stable to Heat, $p H$, and Treatments with Chemicals and Enzymes}

To obtain a preliminary characterization of the antimicrobial molecule, we analyzed its stability in a wide range of $\mathrm{pH}$ and temperature conditions and after treatments with chemicals and enzymes. As reported in Table 2, the molecule was similarly active against its target cells after 1 or $5 \mathrm{~h}$ of incubation at $\mathrm{pH}$ values ranging from 4.0 to 13.0 and was only slightly reduced at $\mathrm{pH} 2.0$. The antimicrobial was fully active after $15 \mathrm{~min}$ of incubation at 60 or $80^{\circ} \mathrm{C}$ and the activity was only reduced after $15 \mathrm{~min}$ at $100{ }^{\circ} \mathrm{C}$ (Table 3). None of the organic solvents or enzymes tested showed any effect on the antimicrobial activity of the small anti-Staphylococcus molecule (Table 3).

Table 2. Effect of $\mathrm{pH}$ on antimicrobial activity.

\begin{tabular}{ccc}
\hline \multirow{2}{*}{$\mathbf{p H}$} & Supernatant Activity $^{\mathbf{a}}<\mathbf{3} \mathbf{~ k D a}$ against S. aureus \\
\cline { 2 - 3 } & $\mathbf{1} \mathbf{h}$ & $\mathbf{5} \mathbf{~ h}$ \\
\hline 2 & 7 & 7 \\
4 & 10 & 10 \\
7 & 10 & 10 \\
10 & 10 & 10 \\
13 & 10 & 10 \\
\hline \multicolumn{2}{c}{ a Diameter (mm) of the inhibition halo in plate assays. }
\end{tabular}

Table 3. Effects of heat, chemicals, and enzymes on antimicrobial activity.

\begin{tabular}{cc}
\hline Treatment & Supernatant Activity $^{\mathbf{b}}<3$ kDa against S. aureus \\
\hline None & 10 \\
Trypsin $^{\mathrm{a}}$ & 10 \\
${\text { Proteinase } \mathrm{K}^{\mathrm{a}}}_{\text {DNase }^{\mathrm{a}}}$ & 10 \\
Ribonuclease A $^{\mathrm{a}}$ & 10 \\
Acetone $^{\mathrm{c}}$ & 10 \\
Ethyl alcohol $^{\mathrm{c}}$ & 10 \\
Chloroform $^{\mathrm{c}}$ & 10 \\
Toluene $^{\mathrm{c}}$ & 10 \\
\hline
\end{tabular}


Table 3. Cont.

\begin{tabular}{cc}
\hline Treatment & Supernatant Activity \\
\hline $\mathbf{b}$ & $<3 \mathbf{k D a}$ against $S$. aureus \\
\hline Incubation $(15 \mathrm{~min})$ at: & 10 \\
$60^{\circ} \mathrm{C}$ & 10 \\
$80^{\circ} \mathrm{C}$ & 5 \\
$100^{\circ} \mathrm{C}$ & 5
\end{tabular}

${ }^{a}$ The enzyme concentration was $100 \mu \mathrm{g} / \mathrm{mL}$ [20]. ${ }^{\mathrm{b}}$ Diameter $(\mathrm{mm})$ of the inhibition halo in plate assays. ${ }^{\mathrm{c}} \mathrm{A} 10 \%$ $(\mathrm{v} / \mathrm{v})$ concentration was used.

\subsection{Purification and Chemical Characterization of the Anti-Staphylococcus Molecule}

The supernatant fraction active against $S$. aureus was extracted with chloroform. Both aqueous and organic phases were tested for antimicrobial activity against $S$. aureus, revealing that the organic phase was endowed with the antimicrobial activity. The ${ }^{1} \mathrm{H}$ NMR spectrum suggested the presence of a complex mixture of compounds (data not shown). To investigate the nature of the antimicrobial molecule, we performed a preliminary purification of the bioactive compound by using a C18 reverse phase column and eluted with acetonitrile and water in different ratios. The obtained fractions were tested to evaluate the antimicrobial activity on S. aureus. The results clearly indicated that the active fraction was eluted with the $50 \%$ acetonitrile solution. The ${ }^{1} \mathrm{H}$ NMR spectrum of the active fraction (Figure 3) suggested the presence of long hydrocarbon chains, due to the intense signals in the range of 0.5-1.5 ppm. In addition, signals appearing between 7.0 and $8.5 \mathrm{ppm}$ strongly suggested $\mathrm{N}-\mathrm{H}$ protons, that together with signals around 4 ppm, indicated a peptide backbone (Figure 3) $[9,15]$.

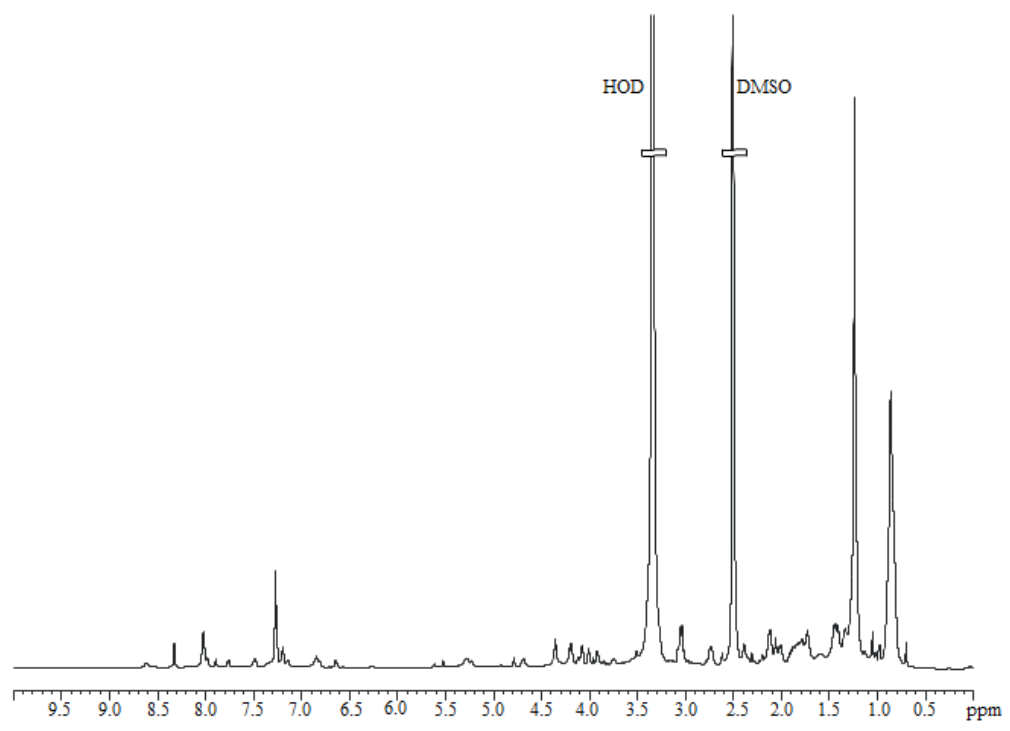

Figure 3. NMR spectrum. ${ }^{1} \mathrm{H}$ NMR spectrum of the active fraction, recorded at $298 \mathrm{~K}$, in DMSO, at $600 \mathrm{MHz}$.

To test if the compounds were lipopeptides, a positive ion mass spectrometry experiment was performed by a MALDI-TOF instrument. The spectrum indicated the presence of several clusters of signals, within the range of $m / z$ 1000-1200. By comparing the $m / z$ values with the mass numbers reported for the lipopeptides commonly produced from Bacillus strains, we found that the signals at $m / z$ 1030.6, 1044.7, 1058.7, and 1072.7 were attributable to the sodium adduct of pumilacidins (Figure 4, Table 4) [15]. 


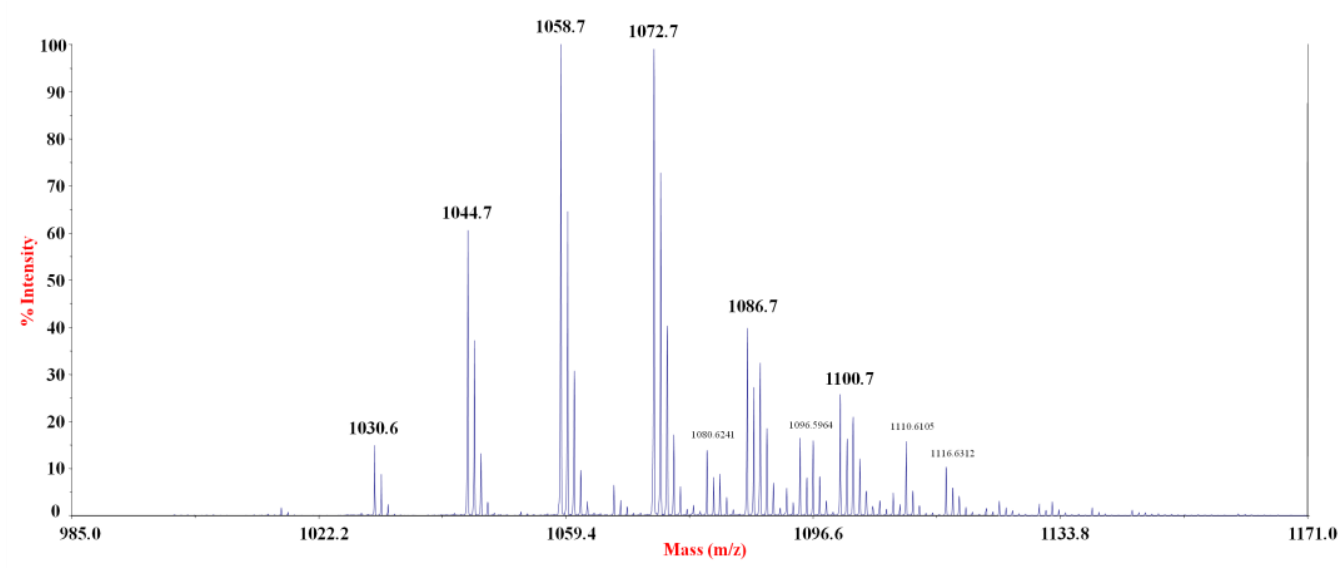

Figure 4. Positive ions MALDI-TOF mass spectrum of the active fraction.

Table 4. Lipopeptide isoforms identified by MALDI-TOF mass spectrometry.

\begin{tabular}{|c|c|c|}
\hline Lipopeptide & {$[\mathrm{M}+\mathrm{Na}]^{+}(\mathrm{m} / \mathrm{z})$} & Isoforms \\
\hline \multirow{6}{*}{ Pumilacidin } & 1030.6 & C13 [Val7] \\
\hline & 1044.7 & C14 [Val7], C13 [Leu/Ile7] \\
\hline & 1058.7 & $\mathrm{C} 15$ [Val7] (pumilacidin B) ${ }^{\mathrm{a}}, \mathrm{C} 14[\mathrm{Leu} / \mathrm{Ile} 7]$ \\
\hline & 1072.7 & C16 [Val7] (pumilacidin F/G) ${ }^{a}, \mathrm{C} 15$ [Leu/lle7] (pumilacidin A) ${ }^{\mathrm{a}}$ \\
\hline & 1086.7 & C17 [Val7] (pumilacidin D) ${ }^{a}, \mathrm{C} 16$ [Leu/Ile7] (pumilacidin E) ${ }^{\mathrm{a}}$ \\
\hline & 1100.7 & C18 [Val7], C17 [Leu/Ile7] (pumilacidin C) ${ }^{\mathrm{a}}$ \\
\hline
\end{tabular}

a See reference [15] for the pumilacidin nomenclature.

Since some pumilacidin isoforms have the same $\mathrm{m} / \mathrm{z}$ values, MS/MS analyses were necessary to identify the amino acid sequence of the peptide portion $[15,21,22]$. The experiments were carried out on the most abundant signals of the mass spectrum. As an example, Figure 5 displays the positive ion MS/MS spectrum obtained from the precursor ion at $m / z$ 1058.7. Through this experiment, it was possible to identify two series of $\boldsymbol{b}^{+}$fragment ions at $m / z$ 959.9-846.7 and $m / z 945.8-832.8$, indicating that at least two isoforms with Val or Leu/Ile at the $C$ terminus, respectively, were present (Figure 5). This was confirmed by the $\mathrm{y}^{+}$fragment ions, since two different series at $m / z 707.5-594.6-481.6$ and $m / z$ 721.6-608.5-495.6 were found (Figure 5). These fragmentation patterns suggested that the signal at $m / z 1058.7$ corresponded to the B isoform, with a $\mathrm{C} 15(3 \mathrm{OH})$ [20]; and to another isoform with a $\mathrm{C} 14(3 \mathrm{OH})$. Similarly, the fragmentation patterns of parent ions at $\mathrm{m} / \mathrm{z} 1044.7$ and $\mathrm{m} / \mathrm{z} 1072.7$ indicated the same amino acid sequences, with different hydroxylated fatty acids (Table 4). Since the signals at $m / z 1030.6,1086.7$, and 1100.7 displayed a low intensity, the corresponding structures reported in Table 4 were suggested by analogy. Some of these pumilacidins have been already characterized [15], as reported in Table 4. However, as far as we know, the isoforms containing 3-hydroxy-tridecanoic, -tetradecanoic, and -octadecanoic fatty acids have not been reported yet. 


\section{Pumilacidin B C15 [Val7] $707.5594 .6481 .6 \quad \mathrm{y}^{+}$ \\ C15- $\beta$-hydroxy fatty acid-Glu-Leu-Leu-Leu-Asp-Leu-Val \\ b $^{+} \quad 846.7959 .9$}

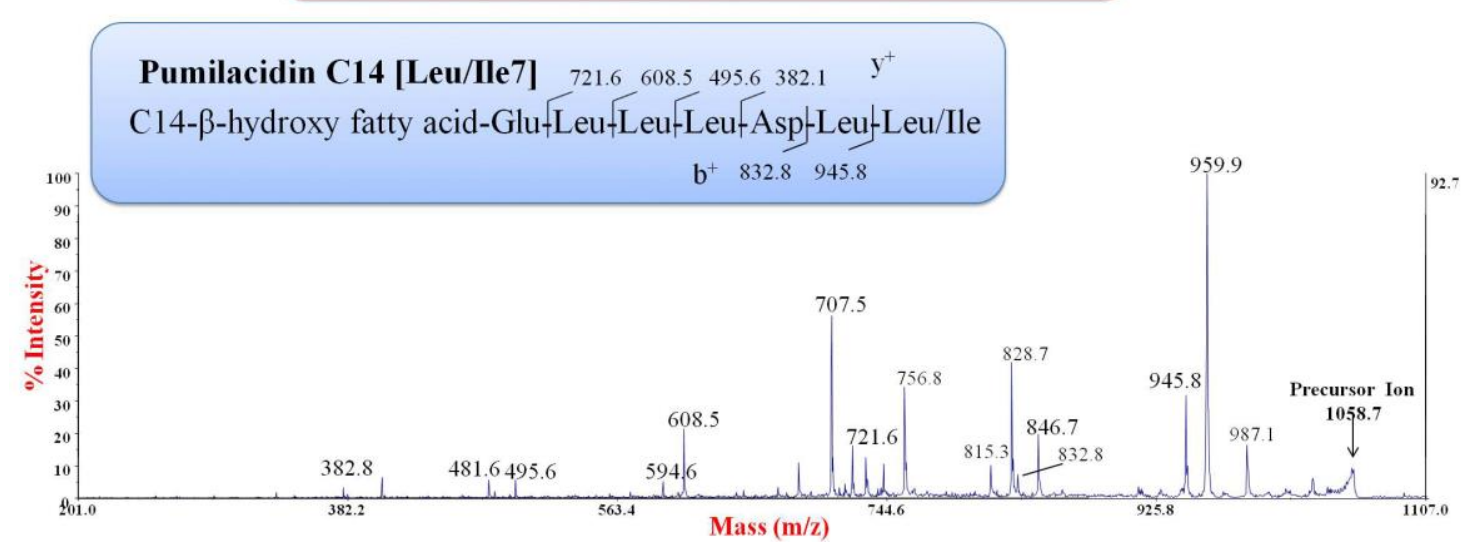

Figure 5. Positive ion MALDI-TOF MS/MS spectrum of the pumilacidin precursor ion at $m / z$ 1058.7. $\mathrm{b}^{+}$and $\mathrm{y}^{+}$fragment ions are reported for pumilacidin isoforms in the insert.

In conclusion, the NMR and MALDI-TOF MS/MS spectra indicated that the anti-Staphylococcus activity was due to a mixture of lipopeptides with structures similar to those of pumilacidins produced by strains of B. pumilus and B. safensis [12,15]. SF214 produced two isoforms of pumilacidin corresponding in their heptapeptide sequences to the previously reported pumilacidins [15] and with hydrophobic chains ranging in size between 13 and 18 carbon atoms (Table 4).

\subsection{The srfA-sfp Locus of SF214}

To characterize the pumilacidin biosynthetic pathway in SF214, we searched the SF214 genome for homologs of genes coding for the NRPS responsible for the nonribosomal synthesis of surfactants in bacilli. A srfA-sfp locus was identified in SF214, and the various genes of the locus showed a high similarity (over $90 \%$ ) with homologs of other pumilacidin-producing strains of the B. pumilus and B. safensis species (Table 5).

Table 5. Genes and putative proteins involved in surfactin/pumilacidin synthesis in B. pumilus SF214,

B. pumilus SAFR-032, and B. safensis U17-1.

\begin{tabular}{|c|c|c|c|c|}
\hline \multirow[b]{2}{*}{ Genes } & \multirow[b]{2}{*}{ Putative Encoded Protein } & \multicolumn{3}{|c|}{ Protein Identity (\%) ${ }^{a}$} \\
\hline & & $\begin{array}{l}\text { B. pumilus SF214 } \\
\text { vs. B. pumilus } \\
\text { SAFR-032 }\end{array}$ & $\begin{array}{l}\text { B. pumilus SF214 } \\
\text { vs. B. safensis } \\
\text { U17-1 }\end{array}$ & $\begin{array}{c}\text { B. pumilus SAFR-032 } \\
\text { vs. B. safensis } \\
\text { U17-1 }\end{array}$ \\
\hline $\operatorname{srfAA}$ & surfactin synthase subunit 1 & 95 & 91 & 90 \\
\hline $\operatorname{srf} A B$ & surfactin synthase subunit 2 & 94 & 91 & 90 \\
\hline srfaC & surfactin synthase subunit 3 & 95 & 93 & 91 \\
\hline $\operatorname{orf} X$ & nonribosomal peptide synthetase & 94 & 91 & 89 \\
\hline $\operatorname{orf} Y$ & nonribosomal peptide synthetase & 94 & 92 & 90 \\
\hline srfAD & surfactin synthase thioesterase subunit & 94 & 89 & 87 \\
\hline 1 & hypothetical protein & - & 87 & - \\
\hline 2 & hypothetical protein & - & 89 & - \\
\hline 3 & hypothetical protein & - & 90 & - \\
\hline 4 & hypothetical protein & - & 84 & - \\
\hline 5 & hypothetical protein & - & 90 & - \\
\hline$y c x C$ & transporter & 96 & 93 & 92 \\
\hline$y c x D$ & transcriptional regulator & 95 & 93 & 93 \\
\hline$s f p$ & $4^{\prime}$-phosphopantetheinyl transferase & 94 & 88 & 88 \\
\hline
\end{tabular}


The srfA operon (Figure 6) was organized in six genes: $\operatorname{srf} A A$, srfAB, and $\operatorname{srf} A C$, coding for the surfactin synthase subunits 1,2 , and 3 respectively; and $\operatorname{srf} A D$, coding for a surfactin synthase thioesterase subunit and two still-uncharacterized genes, orf $X$ and $\operatorname{orf} Y$. These two genes are not present in surfactin- or lychenisin-producing species [12] and are only found in strains of B. pumilus and $B$. safensis that produce pumilacidins [12]. The presence of orf $X / \operatorname{orf} Y$ is the main difference between the srfA operon of the B. pumilus/B. safensis and that of the B. subtilis/B. amyloliquefaciens/ $B$. licheniformis group of surfactant-producing bacilli [12].

All six genes of the srfA operon of SF214 coded for putative proteins with the typical modular organization of NRPS (Figure 7). In particular, srfAA-AC genes coded for proteins arranged in modules of 10, 10, and 4 domains, respectively. In each module of SrfAA and SrfAB of SF214, a condensation domain (C) was followed by an AMP-binding (AMP) and a peptidyl carrier (PCP) domain. The tenth domain of both proteins of SF214 was an additional C domain (Figure 7), while in other pumilacidin-producing bacteria, an epimerization (E) domain was present at the C-terminal part of SrfAA and SrfAB [12]. SrfAC of SF214 had four domains, as in other pumilacidin-producing strains (Figure 7). OrfX and OrfY were characterized by eight and seven domains, respectively. In SF214, the seventh domain of OrfX was a C domain and not an E domain, as in other strains that produce pumilacidins [12]; while OrfY and SrfAD showed the same organization as that of other B. pumilus or B. safensis strains.

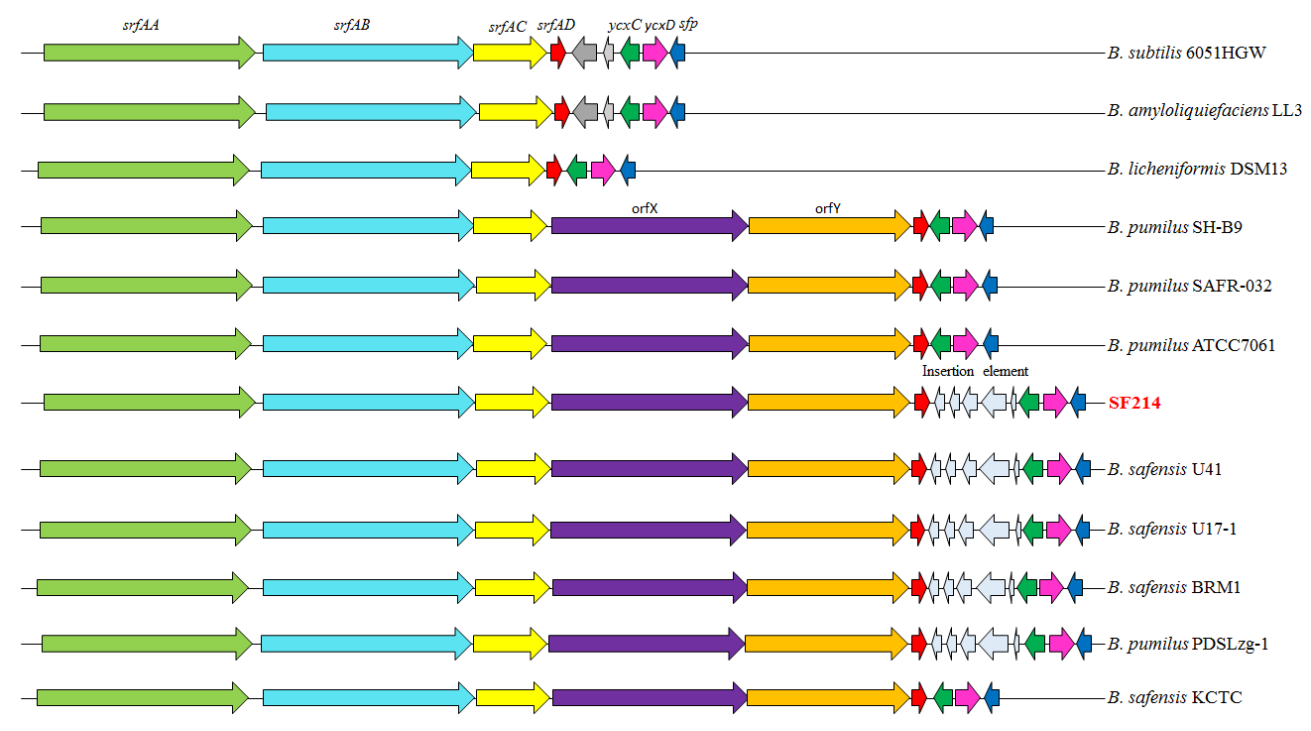

Figure 6. The srfA-sfp locus of surfactant-producing bacilli. Arrows of the same color indicate orthologous genes.

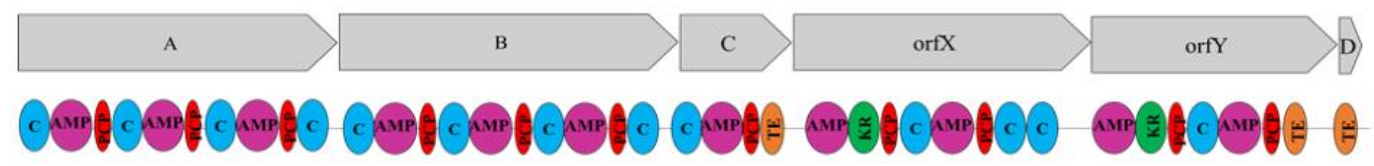

Figure 7. The srfA operon of SF214 and its modular products. The prediction diagram was obtained by using the HMMER tool (https:/ / www.ebi.ac.uk/Tools/hmmer/) [23]. The same colors indicate the same module.

Like in other lychenysin- or pumilacidin-producing bacteria, in SF214, the $y x c$ operon is formed by only two genes, $y c x C$ and $y c x D$, and homologs of $y c x A B$ genes of $B$. subtilis and B. amyloliquefaciens are not found (Figure 6). 
With respect to the group of pumilacidin producers, an additional difference was observed in SF214. It contained an insertion element between $\operatorname{srf} A D$ and $y c x C$, more commonly found in $B$. safensis than in B. pumilus strains [12]; (Figure 6). The insertion element of SF214 coded for five putative products, highly similar (84-87\%) to those encoded by B. safensis strains (Table 5).

The presence of such an insertion element and the high similarity between the B. pumilus and B. safensis species raised the possibility that SF214 was originally [17] misclassified as B. pumilus. To address this point, we performed an accurate phylogenetic analysis based on the 16S RNA and gyrB gene sequences. In both cases, the SF214 sequences shared the highest similarity with sequences of B. pumilus strains (Figure 8), suggesting SF214 as being an isolate of B. pumilus. To confirm this finding, the entire genome of B. pumilus SF214 was compared with the genomes of B. pumilus SAFR-032, B. safensis KCTC, and B. safensis U17. The average nucleotide identity (ANI) values, reported in parentheses, indicated that SF214 is more similar to B. pumilus SAFR-032 $(94.87 \%)$ than to B. safensis KCTC $(92.44 \%)$ and B. safensis U17 (92.40\%).
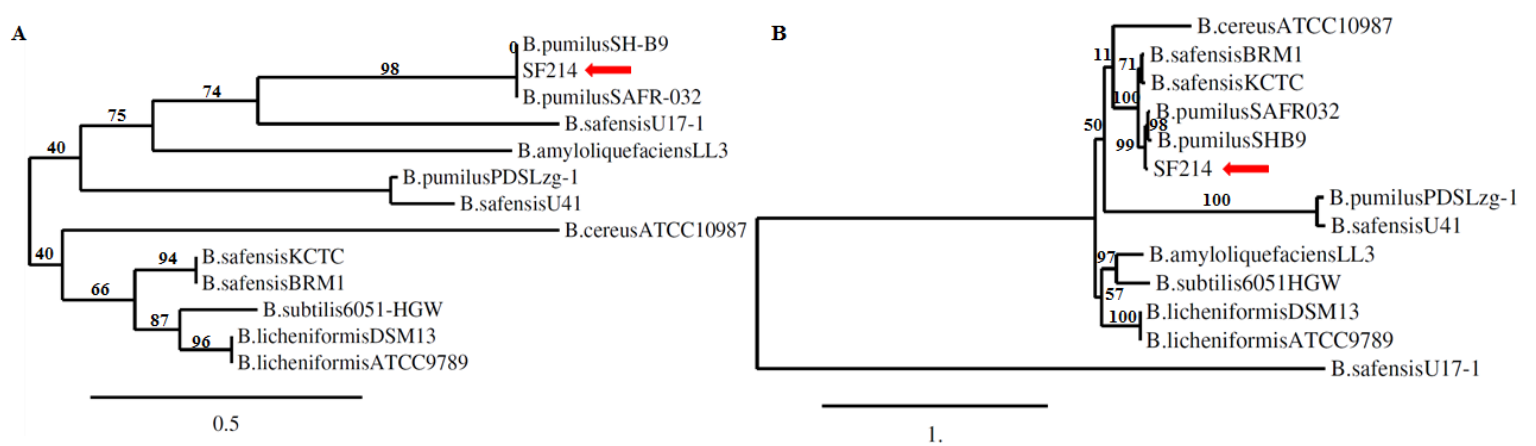

Figure 8. Phylogenetic trees. Diagrams were obtained on the basis of $16 \mathrm{~S}$ rRNA (A) and gyrase B subunit (B) gene sequences (http:/ / www.phylogeny.fr / phylogeny.cgi) [24].

\section{Experimental Section}

\subsection{Bacterial Strains}

Bacillus strains are listed in Table S1 (Supplementary Materials). The antibacterial activity of these strains was evaluated using a panel of indicator strains: six Gram-positive (Streptococcus faecalis, Staphylococcus aureus, Bacillus megaterium, Listeria monocytogenes, Mycobacterium smegmatis, and Enterococcus faecalis) and five Gram-negative (Escherichia coli, Salmonella enterica typhimurium, Pseudomonas fluorescens, Shigella sonnei, and Citrobacter freundii) bacteria [25]. All bacteria were grown in $\mathrm{LB}$ broth $(8 \mathrm{~g} / \mathrm{L} \mathrm{NaCl}, 10 \mathrm{~g} / \mathrm{L}$ tryptone, $5 \mathrm{~g} / \mathrm{L}$ yeast extract $)$ aerobically at $25^{\circ} \mathrm{C}$.

To characterize the antimicrobial production of SF214, the strain was grown at $37^{\circ} \mathrm{C}$ in different media, with a base of DSM (Difco sporulation medium: bacto nutrient broth $8 \mathrm{~g} / \mathrm{L}, \mathrm{KCl} 1 \mathrm{~g} / \mathrm{L}$, and $\mathrm{MgSO}_{4} 0.25 \mathrm{~g} / \mathrm{L}$, sterilized at $121^{\circ} \mathrm{C}$ for $30 \mathrm{~min}$ ). To $1 \mathrm{~L}$ of this solution, $1 \mathrm{~mL}$ of each of the following filter-sterilized solutions were added: $1 \mathrm{M} \mathrm{Ca}\left(\mathrm{NO}_{3}\right)_{2}, 10 \mathrm{mM} \mathrm{MnCl}{ }_{2}$ and $1 \mathrm{mM} \mathrm{FeSO}$; $\mathrm{S} 7(50 \mathrm{mM}$ morpholinepropanesulfonic acid (MOPS) (adjusted to $\mathrm{pH} 7.0$ with $\mathrm{KOH}$ ), $10 \mathrm{mM}\left(\mathrm{NH}_{4}\right)_{2} \mathrm{SO}_{4}, 5 \mathrm{mM}$ potassium phosphate (pH 7.0), $2 \mathrm{mM} \mathrm{MgCl}_{2}, 0.9 \mathrm{mM} \mathrm{CaCl}, 50 \mu \mathrm{M} \mathrm{MnCl}_{2}, 5 \mu \mathrm{M} \mathrm{FeCl}_{3}, 10 \mu \mathrm{M} \mathrm{ZnCl}_{2}$, $2 \mu \mathrm{M}$ thiamine hydrochloride, $20 \mathrm{mM}$ sodium glutamate, $1 \%$ glucose, $0.1 \mathrm{mg} / \mathrm{mL}$ phenylalanine, and $0.1 \mathrm{mg} / \mathrm{mL}$ tryptophan); and brain heart infusion (BHI: beef heart $5 \mathrm{~g} / \mathrm{L}$, calf brains $12.5 \mathrm{~g} / \mathrm{L}$, $\mathrm{Na}_{2} \mathrm{HPO}_{4} 2.5 \mathrm{~g} / \mathrm{L}$, glucose $2 \mathrm{~g} / \mathrm{L}$, peptone $10 \mathrm{~g} / \mathrm{L}$, and $\mathrm{NaCl} 5 \mathrm{~g} / \mathrm{L}$ ).

\subsection{Filter-Sterilized and Size-Fractionated Supernatants}

Bacillus pumilus SF214 [17] was grown in LB broth for $24 \mathrm{~h}$ at $37^{\circ} \mathrm{C}$; the culture was diluted and used to inoculate fresh LB, Difco Sporulation (DS), or S7 media. Cells of SF214 were then grown for $16 \mathrm{~h}$ at $25^{\circ} \mathrm{C}$, where not otherwise specified. The culture was centrifuged $(1000 \times \mathrm{g}$ for $10 \mathrm{~min}$ at Room 
Temperature) and the supernatant filter-sterilized with a 0.22- $\mu \mathrm{m}$ filter (Millipore, Bedford, MA, USA). The supernatants were size-fractionated (3-kDa and 10-kDa cutoff spin column; Centricon, Millipore). Fractions were tested for antimicrobial activity and reported as the diameter (in millimeters) of the inhibition halo in plate assays.

\subsection{Antimicrobial Plate Assay}

Antimicrobial activity was determined with the method described by Schillinger and Lüeke [26] with the following modifications: $10 \mu \mathrm{L}$ of each bacterial culture (strains listed in Table 1) in stationary growth phase were spotted on the surface of a sterile LB agar plate and the spots air-dried. $100 \mu \mathrm{L}$ of an exponential culture of each of the indicator bacterial strains was mixed with $10 \mathrm{~mL}$ of soft agar $(0.7 \%)$ and poured over the plate. The plates were incubated aerobically overnight at $37^{\circ} \mathrm{C}$ and the inhibition halos were measured and reported in $\mathrm{mm}$.

\subsection{Stability of Antimicrobials at Different $\mathrm{pH}$, Temperature, Chemical, and Enzyme Conditions}

Enzymes $(100 \mu \mathrm{g} / \mathrm{mL})$ and $10 \%$ organic solvents (see Table 3) were added to $100 \mu \mathrm{L}$ of culture supernatant. Enzyme-treated samples were incubated $1 \mathrm{~h}$ at $37^{\circ} \mathrm{C}\left(42{ }^{\circ} \mathrm{C}\right.$ in the case of proteinase $\left.\mathrm{K}\right)$ and solvent-treated samples were incubated for 1 and $5 \mathrm{~h}$ at $25^{\circ} \mathrm{C}$, and subsequently, $10 \mu \mathrm{L}$ aliquots were tested for antimicrobial activity as described above. The effects of $\mathrm{pH}$ and heat (Tables 2 and 3 ) on supernatants were analyzed by assaying the antimicrobial activity after 15 min of incubation at 60 , 80 , and $100{ }^{\circ} \mathrm{C}$ and after 1 - and 5 -h incubations at $30^{\circ} \mathrm{C}$ in $50 \mathrm{mM}$ phosphate buffer (pH 6.0), adjusted to the various $\mathrm{pH}$ with $\mathrm{HCl}$ and $\mathrm{NaOH}$.

\subsection{Lipopeptide Purification and Preliminary Analysis}

The fraction active against $S$. aureus was extracted three times with chloroform (v/v 1:1). The organic phases were combined and concentrated in a rotary vacuum evaporator to obtain $18 \mathrm{mg}$. The organic phase was fractionated on a C18 reverse phase column (Sigma, Aldrich, Italy, $30 \mathrm{~mL}$, $40 \mathrm{~cm} \times 0.5 \mathrm{~cm}$, fraction volume $4 \mathrm{~mL}$ ) and eluted with $\mathrm{CH}_{3} \mathrm{CN} / \mathrm{H}_{2} \mathrm{O}$, ranging from $10 \%$ to $100 \%$ of $\mathrm{CH}_{3} \mathrm{CN}$. The collected fractions were tested for antimicrobial activity and the active fraction, eluted with $50 \% \mathrm{CH}_{3} \mathrm{CN}$, was preliminary analyzed by ${ }^{1} \mathrm{H}$ NMR. The sample was dissolved in $0.5 \mathrm{~mL}$ of DMSO- $d_{6}$, and the ${ }^{1} \mathrm{H}$ NMR spectrum was recorded at $298 \mathrm{~K}$ using a BrukerAvance $600 \mathrm{MHz}$ spectrometer equipped with a cryoprobe (Bruker Italia, Milano, Italy).

\subsection{Characterization of Lipopeptide}

MALDI-TOF spectra were acquired in reflector positive mode by using a SCIEX TOF/TOFTM 5800. Fractions were dissolved in $\mathrm{CHCl}_{3} / \mathrm{CH}_{3} \mathrm{OH}(\mathrm{v} / \mathrm{v} 1: 1)$ at a concentration of $1.0 \mathrm{mg} / \mathrm{mL}$, and $0.5 \mu \mathrm{L}$ of the solution was mixed on the plate with $0.5 \mu \mathrm{L}$ of a $20 \mathrm{mg} / \mathrm{mL}$ solution of 2,5-dihydroxy benzoic acid in $\mathrm{CH}_{3} \mathrm{CN} / \mathrm{TFA} 0.1$ (v/v 7:3). The $\mathrm{m} / \mathrm{z}$ values were measured in the range from $\mathrm{m} / \mathrm{z} 500$ to 5000 .

MALDI TOF-MS/MS coupled with CID (Collision-Induced Dissociation) was used to analyze the fragment ions of lipopeptides for further characterization of the amino acid sequence.

\subsection{Bioinformatic Analysis}

The genome of SF214 (PRJNA290581) was analyzed by searching for homologs of the $s r f A-s f p$ locus of other biosurfactant-producing strains of the Bacillus spp. by using a BLAST analysis (http:/ / blast.ncbi.nlm.nih.gov /) [27]. The prediction of the protein structure for the products of the $s r f A$ operon of SF214 was obtained by using the web server HMMER (https:/ / www.ebi.ac.uk/Tools/hmmer/) [23]. For the phylogenetic analysis, the complete $16 \mathrm{~S}$ ribosomal RNA (rRNA) and gyrase subunit B ( $g y r B$ ) gene sequences of SF214 and of closely related type strains of Bacillus species (from GenBank database) were used to obtain two phylogenetic trees by using the web service "Phylogeny.fr" [24]. The genome comparison and the analysis of ANI values were performed using Jspecies software [28,29]. 


\section{Conclusions}

We report that a marine-isolated strain of B. pumilus, SF214, produces and secretes two molecules with antimicrobial activity: a molecule smaller than $3 \mathrm{kDa}$ active against Staphylococcus aureus and a molecule larger than $10 \mathrm{kDa}$ active against Listeria monocytogenes. The anti-Staphylococcus molecule showed the typical expression pattern of secondary metabolites and we focused our attention on the characterization of this small molecule. A mass spectrometry analysis identified the anti-Staphylococcus molecule as a mixture of lipopeptides formed by a cyclic heptapeptide with the sequence Glu-Leu-Leu-Leu-Asp-Leu-[(Leu/Ile)/Val] and a fatty acid with carbon chains variable in length between 13 and 18 atoms. A similar structure is shared by biosurfactants of the surfactin family [11]. Molecules of this family are nonribosomally synthesized and classified as surfactins, produced by strains of B. subtilis and B. amyloliquefaciens; lichenysins, produced by strains of B. licheniformis; and pumilacidins, produced by strains of B. pumilus and B. safensis [12]. These molecules all have very similar structures, with the heptapeptides sharing similar amino acid sequences and the fatty acids having carbon chains of variable length (C12-C18) [12,20]. The surfactant produced by SF214 has hydrophobic chains of highly variable length (C13-C18) and differs from pumilacidins produced by other B. pumilus strains that are characterized by less variability, with chains of C12-C14 [30] or C15-C17 [31].

Additional differences between SF214 and other pumilacidin-producing strains of B. pumilus are in the organization of the sfr $A$-spf locus coding for the multimodular enzyme responsible for the nonribosomal synthesis of the biosurfactant. The SrfA and SrfB proteins are organized in 10 modules, but the epimerization domain present at the C-terminal end of both proteins of other pumilacidic-producing strains is replaced in SF214 by a condensation domain. Moreover, an insertion element of $4684 \mathrm{bp}$, previously identified in members of the B. safensis species, is present in SF214 between $\operatorname{srf} A D$ and $y c x C$.

Understanding whether and how the differences observed in the $s r f A$-sfp locus cause the minor differences observed in the structure of the pumilacidin of SF214 with respect to those of other strains of B. pumilus and B. safensis will be a challenging future perspective opened by this report.

Supplementary Materials: The following are available online at http:/ / www.mdpi.com/1660-3397/16/6/180/s1, Table S1: Marine isolated strains of the Bacillus genus, Table S2: Antimicrobial plate assay with $20 \mathrm{~mL}$ of filter-sterilized supernatant of SF214, Table S3: GenBank accession numbers ${ }^{\mathrm{a}} /$ locus tag $^{\mathrm{b}}$ for the sequences of SF214 and of closely related type strains of Bacillus species used in this study ${ }^{\mathrm{a}}$.

Author Contributions: A.S., E.R., A.C., and L.B. conceived and designed the experiments; M.M.C., A.S., A.C., E.R., and L.B. analyzed the data; A.S., A.C., and R.C. performed the experiments; E.R. and L.B. wrote the paper (original draft); E.R., L.B., and M.M.C. reviewed and edited the paper.

Funding: This research was funded by the "Programma per il finanziamento della ricerca di Ateneo", grant number "DR341 2016" to LB.

Acknowledgments: We thank Gabriele Andrea Lugli and Christian Milani for their contributions in bioinformatic analyses.

Conflicts of Interest: The authors declare no conflict of interest.

\section{References}

1. Agrawal, S.; Acharya, D.; Adholeya, A.; Barrow, C.J.; Deshmukh, S.K. Nonribosomal Peptides from Marine Microbes and their Antimicrobial and Anticancer Potential. Front. Pharmacol. 2017, 8, 828. [CrossRef] [PubMed]

2. Abad, M.J.; Bedoya, L.M.; Bermejo, P. Marine Compounds and their Antimicrobial Activities. In Science against Microbial Pathogens: Communicating Current Research and Technological Advances; Mendez-Vilas, A., Ed.; Formatex: Badajoz, Spain, 2011; pp. 1293-1306.

3. Zhang, D.J.; Liu, R.F.; Li, Y.G.; Tao, L.M.; Tian, L. Two new antifungal cyclic lipopeptides from Bacillus marinus B-9987. Chem. Pharm. Bull. 2010, 58, 1630-1634. [CrossRef] [PubMed] 
4. Desjardine, K.; Pereira, A.; Wright, H.; Matainahu, T.; Kelly, M.; Andersen, R.J. Tauramamide, a lipopeptide antibiotic produced in culture by Brevibacillus laterosporus isolated from a marine habitat: Structure elucidation and synthesis. J. Nat. Prod. 2007, 70, 1850-1853. [CrossRef] [PubMed]

5. Engelhardt, K.; Degnes, K.F.; Kemmler, M.; Bredholt, H.; Fjaervik, E.; Klinkenberg, G.; Sletta, H.; Ellingsen, T.E.; Zotcheu, S.B. Production of a new thiopeptide antibiotic, TP-1161, by a marine Nocardiopsis species. Appl. Environ. Microbiol. 2010, 76, 4969-4976. [CrossRef] [PubMed]

6. Silva-Stenico, M.E.; Souza, C.; Sturion, A.; Keiko, T.; Etchegaray, A.; Possedente, S.; Beraldo, L.A.; Fatima, M. Non-ribosomal peptides produced by Brazilian cyanobacterial isolates with antimicrobial activity. Microbiol. Res. 2011, 166, 161-175. [CrossRef] [PubMed]

7. Martínez Núñez, M.A.; López, V.E. Nonribosomal peptides synthetases and their applications in industry. Sustain. Chem. Process. 2016, 4, 13. [CrossRef]

8. Shaligram, N.S.; Singhal, R.S. Surfactin-A Review on biosynthesis, fermentation, purification and applications. Food Technol. Biotechnol. 2010, 48, 119-134.

9. Liu, X.-Y.; Yang, S.-Z.; Mu, B.-Z. Production and characterization of a C15-surfactin-O-methyl ester by a lipopeptide producing strain Bacillus subtilis HSO121. Process. Biochem. 2009, 44, 1144-1151. [CrossRef]

10. Snook, M.E.; Mitchell, T.; Hinton, D.M.; Bacon, C.W. Isolation and characterization of leu7-surfactin from the endophytic bacterium Bacillus mojavensis RRC 101, a biocontrol agent for Fusarium verticillioides. J. Agric. Food Chem. 2009, 157, 4287-4292. [CrossRef] [PubMed]

11. Inès, M.; Dhouha, G. Lipopeptide surfactants: Production, recovery and pore forming capacity. Peptides 2015, 71, 100-112. [CrossRef] [PubMed]

12. Domingos, D.F.; De Faria, A.F.; Galaverna, R.S.; Eberlin, M.N.; Greenfield, P.; Zucchi, T.D.; Melo, I.S.; Tran-Dinh, N.; Midgley, D.; De Oliveira, V.M. Genomic and chemical insights into biosurfactant production by the mangrove-derived strain Bacillus safensis CCMA-560. Appl. Genet. Mol. Biotechnol. 2015, 99, 3155-3167. [CrossRef] [PubMed]

13. Das, P.; Mukherjee, S.; Sen, R. Antimicrobial potential of a lipopeptide biosurfactant derived from a marine Bacillus circulans. J. Appl. Microbiol. 2008, 104, 1675-1684. [CrossRef] [PubMed]

14. Cao, X.H.; Liao, Z.Y.; Wang, W.Y.; Lu, M.F. Evaluation of a lipopeptide biosurfactant from Bacillus natto TK-1 as a potential source of anti-adhesive, antimicrobial and antitumor activities. Braz. J. Microbiol. 2009, 40, 373-379. [CrossRef] [PubMed]

15. Naruse, N.; Tenmyo, O.; Kobaru, S.; Kamei, H.; Miyaki, T.; Konishi, M.; Oki, T. Pumilacidin, a complex of new antiviral antibiotics production, isolation, chemical properties, structure and biological activity. J. Antibiot. 1990, 43, 267-280. [CrossRef] [PubMed]

16. Xiu, P.; Liu, R.; Zhang, D.; Sun, C. Pumilacidin-Like Lipopeptides Derived from Marine Bacterium Bacillus sp. Strain 176 Suppress the Motility of Vibrio alginolyticus. Appl. Environ. Microbiol. 2017, 83, e00450-17. [CrossRef] [PubMed]

17. Khaneja, R.; Perez-Fons, L.; Fakhry, S.; Baccigalupi, L.; Steiger, S.; To, E.; Sandmann, G.; Dong, T.C.; Ricca, E.; Fraser, P.D.; et al. Carotenoids Found in Bacillus. J. Appl. Microbiol. 2010, 108, 1889-1902. [PubMed]

18. Manzo, N.; Di Luccia, B.; Isticato, R.; D'Apuzzo, E.; De Felice, M.; Ricca, E. Pigmentation and sporulation are alternative cell fates in Bacillus pumilus SF214. PLoS ONE 2013, 8, e62093. [CrossRef] [PubMed]

19. Di Luccia, B.; Riccio, A.; Vanacore, A.; Baccigalupi, L.; Molinaro, A.; Ricca, E. Matrix Production, Pigment Synthesis, and Sporulation in a Marine Isolated Strain of Bacillus pumilus. Mar. Drugs 2015, 13, 6472-6488. [CrossRef] [PubMed]

20. Naclerio, G.; Ricca, E.; Sacco, M.; De Felice, M. Antimicrobial activity of a newly identified bacteriocin of Bacillus cereus. Appl. Environ. Microbiol. 1993, 59, 4313-4316. [PubMed]

21. Yang, H.; Li, X.; Li, X.; Yu, H.; Shen, Z. Identification of lipopeptide isoforms by MALDI-TOF-MS/MS based on the simultaneous purification of iturin, fengycin, and surfactin by RP-HPLC. Anal. Bioanal. Chem. 2015, 407, 2529-2542. [CrossRef] [PubMed]

22. Nawel, J.; Manresa, A.; Rabanal, F.; Ben Ayed, H.; Hmidet, N.; Nasri, M. Structural characterization and identification of cyclic lipopeptides produced by Bacillus methylotrophicus DCS1 strain. J. Chromatogr. B 2017, 1060, 374-386.

23. Finn, R.D.; Clements, J.; Arndt, J.; Miller, B.L.; Wheeler, F.; Schreiber, F.; Bateman, A.; Eddy, S.R. HMMER web server: 2015 update. Nucleic Acids Res. 2015, 43, W30-W38. [CrossRef] [PubMed] 
24. Dereeper, A.; Guignon, V.; Blanc, G.; Audic, S.; Buffet, S.; Chevenet, F.; Dufayard, J.F.; Guindon, S.; Lefort, V.; Lescot, M.; et al. Phylogeny.fr: Robust phylogenetic analysis for the non-specialist. Nucleic Acids Res. 2008, 36, W465-W469. [CrossRef] [PubMed]

25. Baccigalupi, L.; Di Donato, A.; Parlato, M.; Luongo, D.; Carbone, V.; Rossi, M.; Ricca, E.; De Felice, M. Two small, surface-associated factors mediate adhesion of a food-isolated strain of Lactobacillus fermentum to Caco-2 cells. Res. Microbiol. 2005, 56, 830-836. [CrossRef] [PubMed]

26. Shillinger, U.; Lucke, F.K. Antibacterial activity of Lactobacillus sake isolated from meat. Appl. Environ. Microbiol. 1989, 55, 1901-1906.

27. Altschul, S.F.; Gish, W.; Miller, W.; Myers, E.W.; Lipman, D.J. Basic local alignment search tool. J. Mol. Biol. 1990, 215, 403-410. [CrossRef]

28. Richter, M.; Rossello-Mora, R. Shifting the genomic gold standard for the prokaryotic species definition. Proc. Natl. Acad. Sci. USA 2009, 106, 19126-19131. [CrossRef] [PubMed]

29. Konstantinidis, K.T.; Ramette, A.; Tiedje, J.M. The bacterial species definition in the genomic era. Philos. Trans. R. Soc. Lond B Biol. Sci. 2006, 361, 1929-1940. [CrossRef] [PubMed]

30. Brack, C.; Mikolasch, A.; Schlueter, R.; Otto, A.; Becher, D.; Wenger, U.; Albrecht, D.; Riedel, K.; Shauer, F. Antibacterial Metabolites and Bacteriolytic Enzymes Produced by Bacillus pumilus During Bacteriolysis of Arthrobacter citreus. Mar. Biotechnol. 2015, 17, 290-304. [CrossRef] [PubMed]

31. Kalinovskaya, N.I.; Kuznetosova, T.A.; Ivanova, E.P.; Romanenko, L.A.; Voinov, V.G.; Huth, F.; Laatsch, H. Characterization of Surfactin-like Cyclic Depsipeptides Synthesized by Bacillus pumilus from Ascidian Halocynthia aurantium. Mar. Biotechnol. 2002, 4, 179-188. [CrossRef] [PubMed]

(C) 2018 by the authors. Licensee MDPI, Basel, Switzerland. This article is an open access article distributed under the terms and conditions of the Creative Commons Attribution (CC BY) license (http:/ / creativecommons.org/licenses/by/4.0/). 